University of Nebraska - Lincoln

DigitalCommons@University of Nebraska - Lincoln

Sociology Department, Faculty Publications

Sociology, Department of

2003

Self-Mutilation and Homeless Youth: The Role of Family Abuse, Street Experiences, and Mental Disorders

\author{
Kimberly A. Tyler \\ University of Nebraska-Lincoln, kim@ktresearch.net \\ Les B. Whitbeck \\ University of Nebraska-Lincoln, Iwhitbeck2@unl.edu \\ Dan R. Hoyt \\ University of Nebraska-Lincoln, dhoyt2@unl.edu \\ Kurt D. Johnson \\ University of Nebraska-Lincoln
}

Follow this and additional works at: https://digitalcommons.unl.edu/sociologyfacpub

Part of the Sociology Commons

Tyler, Kimberly A.; Whitbeck, Les B.; Hoyt, Dan R.; and Johnson, Kurt D., "Self-Mutilation and Homeless Youth: The Role of Family Abuse, Street Experiences, and Mental Disorders" (2003). Sociology Department, Faculty Publications. 37.

https://digitalcommons.unl.edu/sociologyfacpub/37

This Article is brought to you for free and open access by the Sociology, Department of at DigitalCommons@University of Nebraska - Lincoln. It has been accepted for inclusion in Sociology Department, Faculty Publications by an authorized administrator of DigitalCommons@University of Nebraska - Lincoln. 


\title{
Self-Mutilation and Homeless Youth: The Role of Family Abuse, Street Experiences, and Mental Disorders
}

\author{
Kimberly A. Tyler, Les B. Whitbeck, Dan R. Hoyt, \\ and Kurt D. Johnson
}

University of Nebraska-Lincoln

\begin{abstract}
Self-mutilation, which is the act of deliberately harming oneself, has been overlooked in studies of homeless and runaway youth. Given their high rates of abuse and mental health disorders, which are associated with selfmutilation, homeless and runaway youth provide an ideal sample in which to investigate factors associated with self-mutilation among a nonclinical population. Based on interviews with 428 homeless and runaway youth aged 16 to 19 years in 4 Midwestern states, the current study revealed widespread prevalence of self-mutilation among these young people. Multivariate analyses indicated that sexual abuse, ever having stayed on the street, deviant subsistence strategies, and meeting diagnostic criteria for depression were positively associated with self-mutilation. The findings are interpreted using stress theory and affect-regulation models.
\end{abstract}

One form of health-risk behavior that has been overlooked in studies of homeless and runaway youth is self-mutilation, which is the act of deliberately harming oneself, causing minor to moderate injuries, but not intended as a suicide attempt (Favazza, 1998; Feldman, 1988; Suyemoto, 1998; Vesper, 1996). Self-mutilation includes a number of forms such as cutting, stabbing, and scratching the skin (Smith, Cox, \& Saradjian, 1998). Reasons for self-mutilation include frustration, depression, tension relief, feelings of emptiness, self-punishment, the need to see blood to know one is alive, to release anger, or to detach from a situation (Bennum \& Phil,

Requests for reprints should be sent to Kimberly A. Tyler, Department of Sociology, 717 Oldfather Hall, University of Nebraska, Lincoln, NE 68588-0324. E-mail: ktyler2@unl.edu 
1983; Raine, 1982; Smith et al., 1998; Vesper, 1996). Ross and McKay (1979) suggest that self-mutilation may be an adaptation, which brings about immediate results and in that sense may serve a "therapeutic purpose" for those who self-mutilate (Zila \& Kiselica, 2001). Therefore, a stressful event(s) leads to particular feelings, such as anxiety and depression, and self-mutilation may be the result of this chain (Bennum \& Phil, 1983; Ross \& Heath, 2002).

Although we could not find any article that focused on self-mutilation among homeless and runaway youth, a better understanding among this group is important for several reasons. First, because research finds that early child abuse trauma is associated with self-mutilation (Briere \& Gil, 1998; DiClemente, Ponton, \& Hartley, 1991) and that the majority of homeless and runaway youth have experienced some form of maltreatment (Janus, Archambault, Brown, \& Welsh, 1995; Tyler, Hoyt, \& Whitbeck, 2000), we would expect such youth to have high rates of selfmutilation. Second, given the age range of our sample (i.e., 16-19 years), they are particularly at risk because the first episode of self-mutilation takes place in middle to late adolescence (Suyemoto, 1998; Suyemoto \& MacDonald, 1995). Third, because homeless youth lack a stable residence and supportive adults (Whitbeck \& Hoyt, 1999), they have fewer people to turn to. Additionally, because these youth experience so many transitions, moving back and forth between foster homes, shelters, and group care (Whitbeck \& Hoyt, 1999), their behavior may also go unnoticed; therefore, they are less likely to receive help. Fourth, based on their family backgrounds (i.e., high rates of abuse, rejecting parents, lower parental warmth) (Whitbeck \& Hoyt, 1999), few homeless youth trust adults and therefore may be less likely to ask for help. Finally, they are a group with lots of daily stressors (e.g., having to survive in a street environment) and mental health problems, some resulting from child maltreatment (Cauce et al., 1998; McCormack, Janus, \& Burgess, 1986; Whitbeck, Hoyt, \& Bao, 2000), and mental health problems are linked to self-mutilation. The purpose of the current study is to examine prevalence rates of selfmutilation among homeless and runaway youth as well as risk factors that are associated with this health-risk behavior.

\section{Theoretical Perspective}

Stress theory and affect regulation models provide useful frameworks for understanding the link among family abuse, street experiences, and selfinjurious behaviors. According to Wheaton (1999), stressors are "conditions of threat, demands, or structural constraints that, by their very 
occurrence or existence, call into question the operating integrity of the organism" (p. 177). Although the majority of people adapt to stress and do not develop serious mental illness or behavioral problems, there are a number of individuals who become hopeless and engage in maladaptive behavior. A central issue then is to explain why some adolescents selfmutilate whereas others do not. According to affect-regulation models, "Self-mutilation may be used to express emotion and conflict both to the self and to others, as well as to achieve a sense of control over emotion that threatens to generally overwhelm the individual, her sense of self, and her connectedness to the world" (Suyemoto, 1998, p. 542). In other words, selfmutilation is a way to express and regulate overwhelming or intolerable emotions (e.g., depression) by creating a sense of control (Suyemoto, 1998). This would be especially true for homeless youth who have been neglected and abused. Suyemoto (1998) also noted, "Self-mutilators use self-mutilation to serve different purposes at different times" (p. 550). Therefore, some homeless youth who experience a stressor such as being a victim of assault on the street may become extremely angry and self-mutilation may serve to produce a calming affect. The same youth may later experience feelings of depression and low self-worth while recalling the physical and sexual abuse experienced before running away, and in this instance, self-mutilation may be used to detach from the situation.

As indicated earlier, many stressors exist in the lives of homeless and runaway youth both on the streets and before they leave home. Stressors, such as physical abuse, neglect, and sexual abuse that many homeless and runaway youth have been exposed to in their family of origin (Janus et al., 1995; Tyler et al., 2000), are likely to affect the mental health of these individuals including their ability to express as well as deal with overwhelming emotions (e.g., depression, post-traumatic stress disorder [PTSD]). Other stressors experienced by many homeless youth include leaving home at an early age and having to sleep on the streets. Additionally, being on the streets increases young people's chances of becoming victims of violence and sexual assault (Tyler, Hoyt, Whitbeck, \& Cauce, 2001). Experiencing numerous stressful events, which often lead to feelings of anxiety and depression, may precipitate self-mutilation (Bennum \& Phil, 1983; Ross \& Heath, 2002). As such, self-mutilation, although unorthodox, is a way of dealing with feelings of sadness, depression, anxiety, PTSD, and so on that may arise from exposure to stressful events (Ross \& Heath, 2002). If self-mutilation is an adaptation, which brings about immediate results as suggested by Ross and McKay (1979), in that sense, self-harm may serve a therapeutic purpose for some youth (Zila \& Kiselica, 2001). 


\section{Clinical Studies}

The majority of studies on self-mutilation, which involve clinical samples, have found that physical abuse, sexual abuse, or both are associated with self-mutilation (Briere \& Gil, 1998; Darche, 1990; DiClemente et al., 1991; Lipschitz et al., 1999; Rosenthal, Rinzler, Wallsh, \& Klausner, 1972; van der Kolk, Perry, \& Herman, 1991; Zlotnick et al., 1996). Mental health outcomes associated with self-mutilation include depression, anger, and loneliness (Darche, 1990; Rosenthal et al., 1972; Schwartz, Cohen, Hoffmann, \& Meeks, 1989). In terms of diagnostic outcomes, the likelihood of frequent mutilation is associated with major depression (Dulit, Fyer, Leon, Brodsky, \& Frances, 1994) and a greater number of risktaking and reckless behaviors (Guertin, Lloyd-Richardson, Spirito, Donaldson, \& Boergers, 2001). Consistent with stress theory and affectregulation models, these findings suggest that conditions of threats (i.e., abuse) do affect young people's functioning and their ability to deal with overwhelming emotions, and those who are angry and depressed are more likely to self-mutilate.

The findings are mixed in terms of gender differences. Some studies have found that girls are significantly more likely to self-mutilate than are boys (Lipschitz et al., 1999), whereas other researchers have found no sex differences for either children or adults (Briere \& Gil, 1998; DiClemente et al., 1991; Dulit et al., 1994).

\section{Nonclinical Studies}

Results from studies of self-mutilation in the general population also reveal that childhood abuse is associated with self-mutilation (Briere \& Gil, 1998; Favazza \& Conterio, 1989) and symptoms of depression (Garrison et al., 1993; Ross \& Heath, 2002). The findings are mixed in terms of sex differences and self-mutilation (Briere \& Gil, 1998; Garrison et al., 1993; Ross \& Heath, 2002). That is, Garrison et al. (1993) found little variation in self-mutilation between early adolescent males and females, yet Ross and Heath's (2002) school-based sample yielded significantly higher rates of self-mutilation among girls than among boys.

Prevalence rates of self-mutilation in the general population have been found to be between 3\% and 4\% (Briere \& Gil, 1998; Garrison et al., 1993). For example, Garrison et al. (1993) in their community sample of adolescents, ages 12 to 14 years, found that approximately $3 \%$ of males and females had engaged in self-injurious acts. However, because few studies of self-mutilation in the general population exist, caution should 
be used in interpreting these percentages. The most common method of self-mutilation found among a sample of public school students and a convenience sample of women from the general population included skin cutting followed by self-hitting, burning, and pinching (Favazza \& Conterio, 1989; Ross \& Heath, 2002).

Overall, child sexual abuse and major depression are associated with self-mutilation in both clinical and nonclinical samples. Findings for other correlations (e.g., physical abuse), however, are inconsistent. Few studies were found on the general population (we only found one study that was representative), and studies on clinical samples were small (e.g., $N=14$ ) with some studies including fewer than 5 males, indicating that further evidence is needed before drawing any conclusions. The findings were split in terms of gender; regardless of whether samples included adults or adolescents and regardless of whether clinical or nonclinical samples were used. More descriptive data are needed on larger nonclinical samples as well as studies that use multivariate modeling techniques with multiple indicators.

\section{Present Study}

Although much of the research cited earlier has found a link between abuse and self-mutilation, many of the studies were descriptive and the majority focused only on clinical samples. Other problems include small sample sizes with relatively few males, studies that were dated, and a lack of research on mental disorders and self-mutilation. Suyemoto (1998) has called for more studies and descriptive information from self-mutilators who are not inpatients. Furthermore, we are unaware of any study that has investigated the link among family abuse, street experiences, and mental disorders with self-mutilation among homeless and runaway youth.

The current study improves on previous research by using multivariate analyses to examine factors associated with self-mutilation among a large nonclinical sample of high-risk youth who typically experience widespread trauma including high rates of abuse and neglect, street victimization, and mental health problems. Second, our sample includes approximately equal numbers of males and females, which allowed us to test for gender differences. Finally, our sample includes homeless youth ages 16 to 19 years, which are the peak years for incidence of selfmutilation (Favazza \& Conterio, 1989).

Based on previous findings, we hypothesized that family abuse (neglect or physical abuse and sexual abuse), street exposure (age at first run and ever stayed on the street), street experiences (victimization, deviant 
subsistence strategies, and trading sex), and mental disorders (PTSD and depression) would all be significantly associated with a greater number of self-injurious acts. Because our sample consists of a narrow age range, no age differences were expected. However, we did expect to find higher rates of self-mutilation among gay, lesbian, and bisexual youth because of the stigmatization and isolation they experience in society (Kruks, 1991; Martin \& Hetrick, 1988) compared with their heterosexual counterparts. Finally, because this is a high-risk group of youth and both homeless males and females experience abuse and victimization, no gender differences were expected.

\section{METHOD}

A total of 428 young people (187 males, 241 females) were interviewed directly on the streets and in shelters by full-time specially trained street interviewers in four Midwestern states (Missouri, Iowa, Nebraska, Kansas). Interviewers were instructed to approach shelter residents and locate eligible respondents in areas of the cities where street kids hang out. Young people were interviewed using a systematic sampling strategy that maximized locating homeless and runaway youth. This approach was used because it is well established that it is not possible to randomly sample homeless populations (Wright, Allen, \& Devine, 1995). Interviews were conducted in a variety of locations such as shelter interview rooms, outreach vans, apartments where youth were doubling up with friends or relatives, quiet corners of restaurants, and outside. All interviewers have considerable experience interacting with this group of young people and are familiar with local street cultures. The street interviewers underwent 2 weeks of intensive training regarding computer assisted personal interviewing (CAPI) procedures and administering the University of Michigan Composite International Diagnostic Interview (UM-CIDI). On returning to their shelter locations, they administered several practice interviews with staff and respondents 20 years or older. After completing their practice interviews, the interviewers returned to the university for a second week of training. All interviews were conducted on laptop computers and downloaded electronically to a special secure university server.

Study eligibility required young people to be between the ages of 16 and 19 years and homeless. Our definition of homeless mandated that the youth currently resided in a shelter, on the street, or was living independently (e.g., friends, transitional living) because they had run away, had been pushed out, or had drifted out of their family of origin. 
Study procedures were explained and informed consent was obtained from the youth. They were assured that refusal to participate, refusal of any question, or stopping the interview process would have no effect on current or future services provided by the outreach agency in which the interviewer was placed.

Interviews were conducted in two parts. The first interview consisted of a social history and symptom scale, and the second interview consisted of the diagnostic items. Based on interviewer reports, approximately $90 \%$ of the adolescents who were approached for an initial interview and who met study criteria agreed to participate in the study. Respondents were paid $\$ 25$ for each interview.

\section{Sample}

The sample was almost evenly divided between males (44\%) and females $(56 \%)$. Ages ranged from 16 to 19 years with a mean of 17.4 years. In terms of race and ethnicity, 59\% of the sample was European American, 22\% were non-Hispanic African American, 5\% were Hispanic, and the remaining $14 \%$ were self-identified as American Indian, Asian or Pacific Islander, or biracial. Approximately $15 \%$ of the sample identified themselves as gay, lesbian, or bisexual.

Many of these young people have run from home for the first time at an early age ( $M=13.4$ years). Approximately half of the sample (49\%) spent at least one night directly on the streets. High rates of abuse are also characteristic of this sample, with $25 \%$ being sexually abused on at least one occasion. Broken down by gender, $12 \%$ of males and $36 \%$ of females had been sexually abused. Almost everyone in the sample (95\%) had been physically abused or neglected on at least one occasion. Similar rates were reported for males and females (93\% and 97\%, respectively).

\section{Measures}

Self-mutilation was assessed in the current study using nine items from the Functional Assessment of Self-Mutilation (FASM; Guertin et al., 2001), which is a self-report measure that asked youth if they had ever engaged in self-injurious behavior (see Table 1 for a list of items). Response categories were 0 (no) and 1 (yes). The nine items were summed such that the higher the score, the greater the number of different self-injurious acts that the youth had engaged in. Of the total sample, $69 \%$ indicated that they had done one of these behaviors on at least one occasion. Cronbach's alpha for this scale was .66. Although this coefficient is low, the individual items 


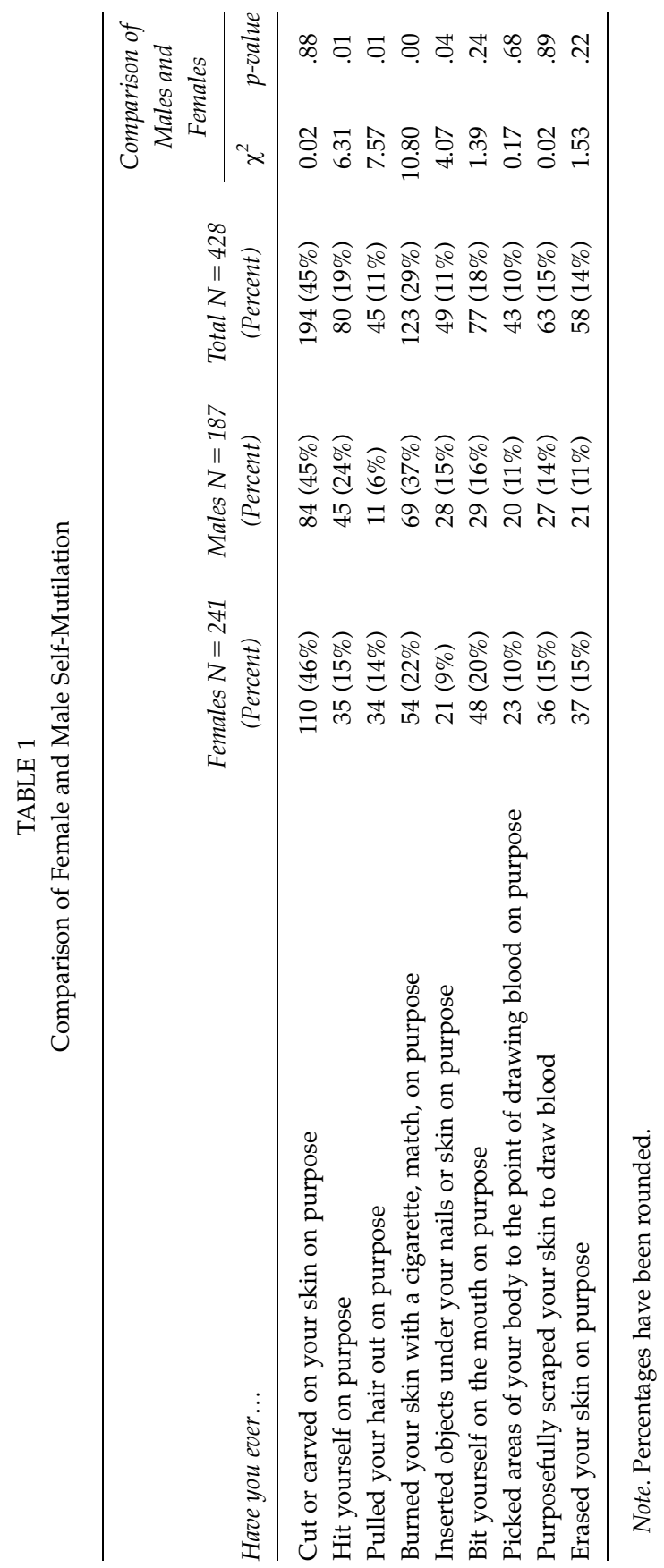


are conceptually related. This coefficient is also similar to that found by the authors of the scale in their study of adolescents (Guertin et al., 2001).

The measure of neglect or physical abuse consisted of nine items. The seven physical abuse items were from the Conflict Tactics Scale (Straus \& Gelles, 1990). Youth were asked to report (before their leaving home) how often any adult who was taking care of them threw something at them in anger, pushed or shoved in anger, hit them with some object, slapped them, beat them up with their fists, threatened them with a gun or knife, and wounded or physically hurt them with a gun or knife. Two items on neglect included being punished by being made to go a full day without food or water and being abandoned for at least 24 hours. Response categories for all items ranged from 0 (never) to 3 (more than five times). The nine items were summed such that a higher score was associated with more neglect or physical abuse. The range of scores was 0 to 27 with a mean of 10.56 (median $=10.0)$. Cronbach's alpha for the nine items was .83 .

The measure of sexual abuse included two items that asked respondents before leaving home, how often any adult who was taking care of them ever asked them to do something sexual and how often any adult ever made them do something sexual or messed around with them sexually. Response categories ranged from 0 (never) to 3 (more than five times). The two items were summed but because this variable was highly skewed, it was dichotomized into $0=$ never sexually abused and $1=$ sexually abused at least once. The bivariate correlation between these two items was .86 .

The measure of age at first run was a single item that asked youth how old they were when they left home for the first time.

Ever stayed on the street was measured by asking youth if they had ever spent one or more nights on the street in an abandoned building or another place out in the open.

The measure of victimization consisted of six items that encompassed sexual victimization and physical victimization since the youth had been on the street. Youth were asked to indicate how often they had been beaten up, robbed, asked to do something sexual that they did not want to do, sexually assaulted or raped, threatened with a weapon, and assaulted and wounded with a weapon. Response categories ranged from 0 (never) to 2 (two or more times). The six items were averaged to form a scale of victimization, with a higher score indicating greater victimization. Cronbach's alpha for this scale was .72.

Deviant subsistence strategies was measured using three items that focused on different tactics that youth may have used since being on the street including stealing, shoplifting, and selling drugs to survive. 
Response categories included 0 (no) and 1 (yes). A count was done to form a scale of deviant subsistence strategies.

The measure of traded sex consisted of three items in which youth were asked if they had ever traded sex for food or shelter, money, or drugs. Response categories included 0 (no) and 1 (yes). A count was done, but because of skewness, this variable was dichotomized into $0=$ never traded sex and $1=$ traded sex at least once.

The UM-CIDI was used to assess major depressive episode and PTSD. The UM-CIDI is based on Diagnostic and Statistical Manual-III-R (DSMIII-R) criteria and represents the University of Michigan revision of the CIDI (World Health Organization, 1990) used in the National Comorbidity Study (Kessler, 1994a, 1994b, Wittchen \& Kessler, 1994). The CIDI (World Health Organization, 1990), from which the UM-CIDI is derived, is a wellestablished diagnostic instrument (see Wittchen, 1994, for review) that has shown excellent interrater reliability, test-retest reliability, and validity for the diagnoses that were used in this study. The UM-CIDI is considered the best diagnostic instrument for use with large population samples down to age 15 years. In the current study, 30\% of youth met diagnostic criteria for major depression and approximately $36 \%$ of all young people met diagnostic criteria for PTSD.

Control variables included age, gender, and sexual orientation. Respondent ages ranged from 16 to 19 with a mean of 17.4 years. Gender was coded $0=$ males, $1=$ females. Sexual orientation was dichotomized into $0=$ heterosexual and $1=$ gay, lesbian, or bisexual, with approximately $15 \%$ of the sample self-identifying as the second group.

\section{RESULTS}

Engaging in self-mutilative behavior was prevalent among this sample of homeless youth, where $69 \%$ indicated that they had done this at least once. There was no significant difference between males and females in terms of the number of different self-injurious acts ( $72 \%$ of males vs. $66 \%$ of females self-mutilated). Of those who self-mutilated, $54 \%$ reported engaging in three or fewer different types of self-mutilation. The most frequently cited form of self-mutilation was cutting or carving of the skin, as reported by $45 \%$ of youth (see Table 1). Although there was no difference between males and females in terms of the overall number of different selfinjurious acts, there were some significant differences in terms of the specific types of self-mutilation (see Table 1).

As a result of having engaged in self-injurious acts (results not shown), $12 \%(n=28)$ reported that they had received medical attention. In terms of 
the pain that they experienced while doing these things to themselves in the past 12 months, $47 \%(n=106)$ said that they felt no pain, 36\% $(n=82)$ said they felt little pain, $12 \%(n=28)$ said the pain was moderate, and $4 \%$ $(n=10)$ said the pain was severe.

Table 2 presents the bivariate correlations, means, and standard deviations for all study variables. With the exception of gender, selfmutilation was correlated with all the study variables. These correlations are statistically significant but are small to moderate in size (Cohen, 1988).

Table 3 presents multiple regression models for correlates of selfmutilation. Because we wanted to see the individual effect of abuse at home versus street exposure, street experiences, and diagnostic variables on self-mutilation, we entered the variables in five blocks. Model 1 (only the control variables were included) revealed that age and sexual orientation was significantly related to self-mutilation. Older youth ( $\beta=.11)$ and gay, lesbian, or bisexual youth $(\beta=.15)$ reported a greater number of self-injurious acts. Sexual orientation was significant in Models 1 through 4, although age dropped out by Model 2. Adding in the family abuse variables (Model 2 ) revealed that neglect or physical abuse $(\beta=.22)$ and sexual abuse $(\beta=.18)$ were significantly associated with selfmutilation. The family abuse variables accounted for $9 \%$ of the variance in self-mutilation beyond the control variables.

Model 3 added street exposure and revealed that age at first run $(\beta=$ $-.11)$ and ever staying on the street $(\beta=.21)$ was significantly associated with self-mutilation. The street exposure variables accounted for an additional $4 \%$ of the variance in self-mutilation. Street experiences were added in Model 4, which revealed that victimization and deviant subsistence strategies were significantly related to self-mutilation. These variables accounted for an additional $3 \%$ of the variance. Finally, adding in the diagnostic variables in Model 5 revealed that major depression was significant ( $\beta=.13$ ) as were deviant subsistence strategies $(\beta=.13)$, ever staying on the street ( $\beta=.13)$, and sexual abuse ( $\beta=.11)$. The diagnostic variables accounted for an additional $3 \%$ of the variance in self-mutilation. In a final model (results not shown) we tested for all possible interactions (with age, gender, and sexual orientation) but none was significant.

\section{DISCUSSION}

Many youth in the current study experienced high rates of family abuse, mental disorders, and prevalence of different self-injurious acts. Consistent with the literature on studies of both clinical and nonclinical samples (cf. Briere \& Gil, 1998; Darche, 1990; Garrison et al., 1993; Ross \& 


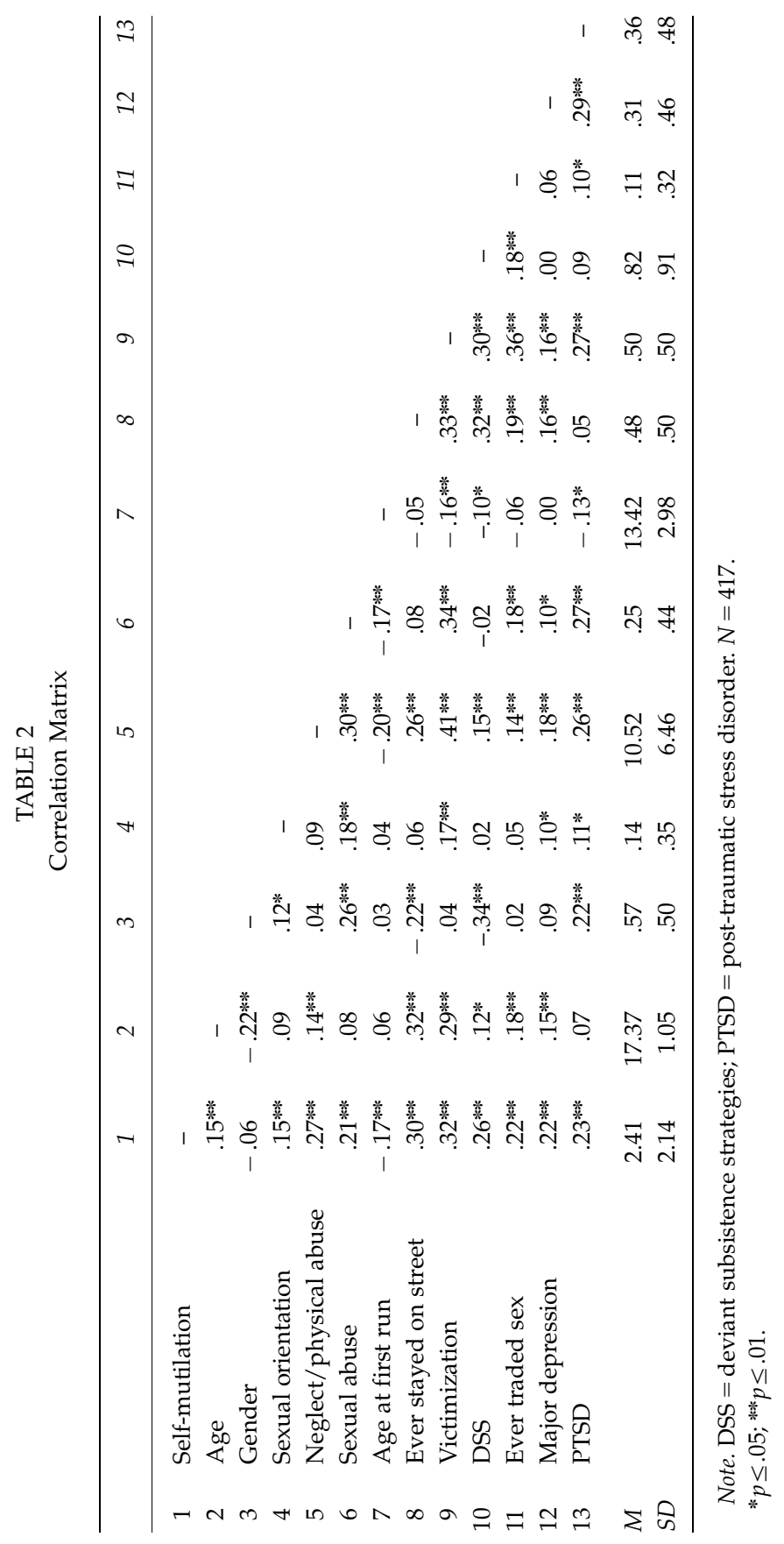




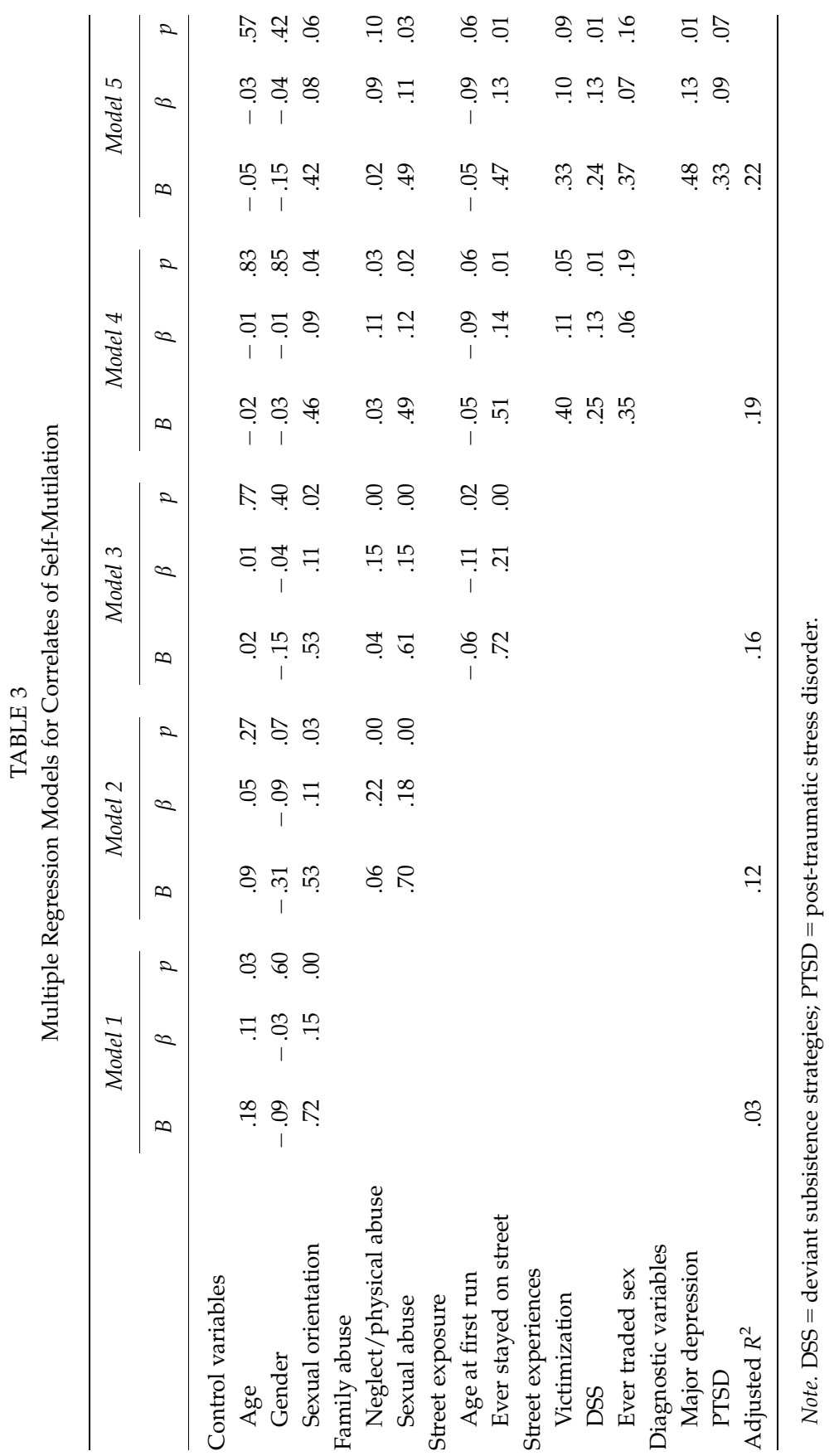


Heath, 2002; Zlotnick et al., 1996), self-mutilation was associated with sexual abuse and depression.

Although previous research on homeless and runaway youth has not focused on self-mutilation, the current findings indicate that engaging in self-injurious acts is widespread among these youth and poses a serious health concern. In the current study $69 \%$ of the youth reported that they had engaged in some form of self-injurious acts on at least one occasion, with cutting or carving of the skin being the most common form reported by $45 \%$ of youth. The literature also found that cutting is the most frequently used method of self-mutilation (cf. Favazza \& Conterio, 1989; Suyemoto, 1998; Suyemoto \& MacDonald, 1995).

Congruent with the literature on clinical samples and the general population, youth who experienced severe trauma as a child were more likely to self-mutilate. Similarly, other stressors that these youth experienced that were associated with self-mutilation included leaving home at an early age, staying on the street, being victimized, and participating in deviant subsistence strategies. Suffering from mental disorders (i.e., major depression) was also associated with self-mutilation. It is possible that those who experience numerous stressors (e.g., different forms of child maltreatment) may use self-mutilation as a way to express themselves or to regulate overwhelming emotions of depression. Furthermore, because some individuals use self-mutilation to serve different purposes at different times (Suyemoto, 1998), homeless youth that experience additional street stressors (e.g., victimization, having to sleep on the street) may later self-mutilate to regulate their emotions associated with these stressful life events. Therefore, self-mutilation may be used to calm the youth in one instance but to inflict pain or selfpunishment at a later time.

Overall, this study has been useful for identifying important risk factors for self-mutilation among a sample of homeless youth. Although we did not fully test stress theory and affect-regulation models, they do offer useful explanations for why some homeless and runaway youth may selfmutilate. Numerous stressors, such as child maltreatment, having to live on the streets, and being a victim of physical or sexual assault, exist in the lives of these young people and such factors were associated with selfmutilation. Because abuse and victimization have been found to be associated with feelings of anger, depression, PTSD, frustration, feeling isolated, and so on (cf. Beitchman, Zucker, Hood, DaCosta, \& Akman, 1991), some youth may feel the need to regulate such emotions so as not to feel overwhelmed to the point of not being able to function properly on a daily basis. According to Wheaton (1999), such stressors affect the ability of the person to operate and can affect their well-being. If young people are 
experiencing such feelings (e.g., depression) and such feelings can lead to self-mutilation (Bennum \& Phil, 1983; Smith et al., 1998), it is possible that a chain does exist whereby stressors bring on particularly negative feelings, and for some individuals, self-harm may be a way to express those feelings or a way to externalize emotions. Selfmutilation may also be a way to regulate their emotions, which they may view as overwhelming and intolerable. Given that homeless youth have high rates of abuse and high rates of mental disorders, they are a group at high-risk for self-mutilation and a population in need of further study.

The current study provides unique findings in terms of prevalence of self-injurious acts and risk factors associated with self-mutilation among a sample of homeless and runaway youth. However, some limitations need to be addressed. First, results of the present study are limited by respondents' self-reports. However, participants were informed that their responses would be confidential, and the interviewers were familiar with local street cultures and were already known and trusted by many of the runaways. For these reasons, it is less likely that the respondents would be motivated to bias their responses. Moreover, comparisons done on runaway adolescents and their parents revealed that these young people do not appear to be overreporting abuse within the home (Whitbeck, Hoyt, \& Ackley, 1997). Another limitation is the retrospective nature of some of the measures, which may have resulted in some over- or underreporting. Also, we do not have any clinical assessments of selfmutilation with which to compare our scale, and stronger measures of self-mutilation are needed. We also caution that the current findings are based on cross-sectional data and even though child maltreatment, street exposure and experiences, and mental disorders were associated with self-mutilation, we cannot prove causation; therefore, our multivariate results should be interpreted with caution. Furthermore, most correlations were small to modest in magnitude.

Given the cross-sectional nature of our data, we were unable to test fully stress theory and affect-regulation models and examine causal linkages. Therefore, using longitudinal data, we encourage future research to examine whether mental disorders are the result of early life stressors that lead to self-mutilation as we have hypothesized, or whether selfmutilation may exacerbate the risk for a variety of mental disorders. We believe that stress theory or affect-regulation models could be useful for examining such linkages. Additionally, sense of control, self-regulatory processes of the self, and social networks could be explored as possible intervening variables. Other areas that could provide valuable information about this process include gaining information on how participants 
define self-mutilation, their interpretation of it, and whether one-time selfmutilators and repeaters are distinct groups.

In summary, the current study revealed that $69 \%$ of these youth engaged in some form of self-mutilation on at least one occasion and that $12 \%$ reported receiving medical attention as a result. This prevalence rate, coupled with the rates of mental disorders found among these young people, poses a serious health concern. Sexual abuse before running away, ever having stayed on the street, deviant subsistence strategies, and major depression were associated with an increase in the number of different self-injurious acts. Without intervention, some of these young people will continue invoking maladaptive strategies such as self-mutilation, which is likely to negatively affect both their physical and mental health.

\section{ACKNOWLEGMENT}

This research was funded by the National Institute of Mental Health (MH 57110).

\section{REFERENCES}

Beitchman, J. H., Zucker, K. J., Hood, J. E., DaCosta, G. A., \& Akman, D. (1991). A review of the short-term effects of child sexual abuse. Child Abuse and Neglect, 15, 537-556.

Bennum, I., \& Phil, M. (1983). Depression and hostility in self-mutilation. Journal of Suicide and Life Threatening Behavior, 13, 71-84.

Briere, J., \& Gil, E. (1998). Self-mutilation in clinical and general population samples: Prevalence, correlates, and functions. American Journal of Orthopsychiatry, 68, 609-620.

Cauce, A. M., Paradise, M., Embry, L., Morgan, C. J., Lohr, Y., \& Theofelis, J., et al. (1998). Homeless youth in Seattle: Youth characteristics, mental health needs, and intensive case management. In K. Kutash, A. Duchnowski, \& M. Epstein (Eds.), Community-based programming for children with serious emotional disturbances: Research and evaluation (pp. 611632). Baltimore: Brookes.

Cohen, J. (1988). Statistical power analysis for the behavioral sciences. Hillsdale, NJ: Erlbaum.

Darche, M. A. (1990). Psychological factors differentiating self-mutilating and non-selfmutilating adolescent inpatient females. Psychiatric Hospital, 21, 31-35.

DiClemente, R. J., Ponton, L. E., \& Hartley, D. (1991). Prevalence and correlates of cutting behavior: Risk for HIV transmission. Journal of the American Academy of Child \& Adolescent Psychiatry, 30, 735-739.

Dulit, R. A., Fryer, M. R., Leon, A. C., Brodsky, B. S., \& Frances, A. J. (1994). Clinical correlates of self-mutilation in borderline personality disorder. American Journal of Psychiatry, 151, 1305-1311.

Favazza, A. R. (1998). The coming of age of self-mutilation. Journal of Nervous and Mental Disease, 186, 259-268.

Favazza, A. R., \& Conterio, K. (1989). Female habitual self-mutilators. Acta Psychiatr Scand, 79, 283-289. 
Feldman, M. D. (1988). The challenge of self-mutilation: A review. Comprehensive Psychiatry, 29, 252-269.

Garrison, C. Z., Addy, C. L., McKeown, R. E., Cuffe, S. P., Jackson, K. L., \& Waller, J. L. (1993). Nonsuicidal physically self-damaging acts in adolescents. Journal of Child and Family Studies, 2, 339-352.

Guertin, T., Lloyd-Richardson, E., Spirito, A., Donaldson, D., \& Boergers, J. (2001). Selfmutilative behavior in adolescents who attempt suicide by overdose. Journal of the American Academy of Child and Adolescent Psychiatry, 40, 1062-1069.

Janus, M. D., Archambault, F. X., Brown, S. W., \& Welsh, L. A. (1995). Physical abuse in Canadian runaway adolescents. Child Abuse \& Neglect, 19, 433-447.

Kessler, R. C. (1994a). The national comorbidity survey of the United States. International Review of Psychiatry, 6, 365-376.

Kessler, R. C. (1994b). Building on the ECA: The national comorbidity survey and the children's ECA. International Journal of Methods in Psychiatric Research, 4, 81-94.

Kruks, G. (1991). Gay and lesbian homeless/street youth: Special issues and concerns. Journal of Adolescent Health, 12, 515-518.

Lipschitz, D. S., Wingegar, R. K., Nicolaou, A. L., Hartnick, E., Wolfson, M., \& Southwick, S. M. (1999). Perceived abuse and neglect as risk factors for suicidal behavior in adolescent inpatients. Journal of Nervous and Mental Disease, 187, 32-39.

Martin, A. D., \& Hetrick, E. S. 1988. The stigmatization of the gay and lesbian adolescent. Journal of Homosexuality, 15, 163-183.

McCormack, A., Janus, M., \& Burgess, A. W. (1986). Runaway youths and sexual victimization: Gender differences in an adolescent runaway population. Child Abuse $\mathcal{E}$ Neglect, 10, 387-395.

Raine, W. J. B. (1982). Self-mutilation. Journal of Adolescence, 5, 1-13.

Rosenthal, R. J., Rinzler, C., Wallsh, R., \& Klausner, E. (1972). Wrist-cutting syndrome: The meaning of a gesture. American Journal of Psychiatry, 128, 47-52.

Ross, S., \& Heath, N. (2002). A study of the frequency of self-mutilation in a community sample of adolescents. Journal of Youth and Adolescence, 31, 67-77.

Ross, R. R., \& McKay, H. B. (1979). Self-mutilation. Lexington, MA: Lexington Book.

Schwartz, R. H., Cohen, P., Hoffmann, N. G., \& Meeks, J. E. (1989). Self-harm behaviors (carving) in female adolescent drug abusers. Clinical Pediatrics, 28, 340-346.

Smith, G., Cox, D., \& Saradjian, J. (1998). Women and self-harm: Understanding, coping, and healing from self-mutilation. London: Women's Press.

Straus, M., \& Gelles, R. (1990). Physical violence in American families. New Brunswick, NJ: Transaction.

Suyemoto, K. L. (1998). The functions of self-mutilation. Clinical Psychology Review, 18, 531554.

Suyemoto, K. L., \& MacDonald, M. L. (1995). Self-cutting in female adolescents. Psychotherapy, $32,162-171$.

Tyler, K. A., Hoyt, D. R., \& Whitbeck, L. B. (2000). The effects of early sexual abuse on later sexual victimization among female homeless and runaway youth. Journal of Interpersonal Violence, 15, 235-250.

Tyler, K. A., Hoyt, D. R., Whitbeck, L. B., \& Cauce, A. M. (2001). The impact of childhood sexual abuse on later sexual victimization among runaway youth. Journal of Research on Adolescence, 11, 151-176.

van der Kolk, B. A., Perry, J. C., \& Herman, J. L. (1991). Childhood origins of self-destructive behavior. American Journal of Psychiatry, 148, 1665-1671.

Vesper, J. H. (1996). Ethical and legal considerations with self mutilating and lethal clients. American Journal of Forensic Psychology, 14, 25-38. 
Wheaton, B. (1999). The nature of stressors. In A. V. Horwitz, \& T. L. Scheid (Eds.), A handbook for the study of mental health: Social contexts, theories, and systems (pp. 176-197). New York: Cambridge University Press.

Whitbeck, L. B., \& Hoyt, D. R. (1999). Nowhere to grow: Homeless and runaway adolescents and their families. New York: Aldine de Gruyter.

Whitbeck, L. B., Hoyt, D. R., \& Ackley, K. A. (1997). Families of homeless and runaway adolescents: A comparison of parent/caretaker and adolescent perspectives on parenting, family violence, and adolescent conduct. Child Abuse \& Neglect, 21, 517-528.

Whitbeck, L. B., Hoyt, D. R., \& Bao, W. (2000). Depressive symptoms and co-occurring depressive symptoms, substance abuse, and conduct problems among runaway and homeless adolescents. Child Development, 71, 721-732.

Wittchen, H. U. (1994). Reliability and validity studies of the WHO-composite international diagnostic interview (CIDI): A critical review. Psychiatric Research, 28, 57-84.

Wittchen, H. U., \& Kessler, R. C. (1994). Modifications of the CIDI in the National Comorbidity Study: The development of the UM-CIDI. Ann Arbor, MI: NCS Working Paper 2.

World Health Organization. (1990). Composite international diagnostic interview (CIDI) (Version 1.0. Geneva: World Health Organization.

Wright, J. D., Allen, T. L., \& Devine, J. A. (1995). Tracking non-traditional populations in longitudinal studies. Evaluation and Program Planning, 18, 267-277.

Zila, L. M., \& Kiselica, M. S. (2001). Understanding and counseling self-mutilation in female adolescents and young adults. Journal of Counseling $\mathcal{E}$ Development, 79, 46-52.

Zlotnick, C., Shea, M. T., Pearlstein, T., Simpson, E., Costello, E., \& Begin, A. (1996). The relationship between dissociative symptoms, alexithymia, impulsivity, sexual abuse, and self-mutilation. Comprehensive Psychiatry, 37, 12-16. 